\title{
NBCe1 Mediates the Acute Stimulation of Astrocytic Glycolysis by Extracellular $\mathrm{K}^{+}$
}

\author{
Iván Ruminot, ${ }^{1,2}$ Robin Gutiérrez, ${ }^{1,2}$ Gaspar Peña-Münzenmayer, ${ }^{1,2}$ Carolina Añazco, ${ }^{1}$ Tamara Sotelo-Hitschfeld, ${ }^{1,2}$ \\ Rodrigo Lerchundi, ${ }^{1,2}$ María Isabel Niemeyer, ${ }^{1}$ Gary E. Shull, ${ }^{3}$ and L. Felipe Barros ${ }^{1}$ \\ ${ }^{1}$ Centro de Estudios Científicos (CECs), Valdivia, Chile, ${ }^{2}$ Universidad Austral de Chile, Valdivia, Chile, and ${ }^{3}$ Department of Molecular Genetics, \\ Biochemistry, and Microbiology, University of Cincinnati College of Medicine, Cincinnati, Ohio 45267
}

Excitatory synaptic transmission stimulates brain tissue glycolysis. This phenomenon is the signal detected in FDG-PET imaging and, through enhanced lactate production, is also thought to contribute to the fMRI signal. Using a method based on Förster resonance energy transfer in mouse astrocytes, we have recently observed that a small rise in extracellular $\mathrm{K}^{+}$can stimulate glycolysis by $>300 \%$ within seconds. The $\mathrm{K}^{+}$response was blocked by ouabain, but intracellular engagement of the $\mathrm{Na}^{+} / \mathrm{K}^{+}$ATPase pump with Na ${ }^{+}$was ineffective, suggesting that the canonical feedback regulatory pathway involving the $\mathrm{Na}^{+}$pump and ATP depletion is only permissive and that a second mechanism is involved. Because of their predominant $\mathrm{K}^{+}$permeability and high expression of the electrogenic $\mathrm{Na}^{+} / \mathrm{HCO}_{3}^{-}$ cotransporter $\mathrm{NBCe}$, astrocytes respond to a rise in extracellular $\mathrm{K}^{+}$with plasma membrane depolarization and intracellular alkalinization. In the present article, we show that a fast glycolytic response can be elicited independently of $\mathrm{K}^{+}$by plasma membrane depolarization or by intracellular alkalinization. The glycolytic response to $\mathrm{K}^{+}$was absent in astrocytes from NBCe1 null mice (Slc4a4) and was blocked by functional or pharmacological inhibition of the NBCe1. Hippocampal neurons acquired $\mathrm{K}^{+}$-sensitive glycolysis upon heterologous NBCe1 expression. The phenomenon could also be reconstituted in HEK293 cells by coexpression of the NBCe1 and a constitutively open $\mathrm{K}^{+}$channel. We conclude that the NBCel is a key element in a feedforward mechanism linking excitatory synaptic transmission to fast modulation of glycolysis in astrocytes.

\section{Introduction}

Neural activity is accompanied by a transient imbalance between the usage of glucose and the usage of $\mathrm{O}_{2}$ (Fox et al., 1988). Reflecting this mismatch, a local surge in lactate concentration can be detected within seconds (Prichard et al., 1991; Hu and Wilson, 1997a; Caesar et al., 2008) that coincides with a decrease in interstitial glucose (Silver and Erecińska, 1994; Hu and Wilson, 1997b). Multiple roles have been ascribed to lactate in the brain, including preferential fueling of neurons (Pellerin and Magistretti, 1994; Suzuki et al., 2011), intercellular signaling (Lam et al., 2005; Shimizu et al., 2007; Gordon et al., 2008), and macromolecular synthesis (Rinholm et al., 2011), but there is no consensus on whether the lactate surge is produced by astrocytes or by neurons, nor there is agreement about the subcellular mechanisms

Received May 4, 2011; revised July 2, 2011; accepted July 27, 2011.

Author contributions: I.R., M.I.N., and L.F.B. designed research; I.R., R.G., G.P.-M., C.A., T.S.-H., R.L., M.I.N., and G.E.S. performed research; G.E.S. contributed unpublished reagents/analytic tools; I.R., R.G., G.P.-M., C.A., T.S.-H., R.L., M.I.N., G.E.S., and L.F.B. analyzed data; I.R. and L.F.B. wrote the paper.

This work was partially funded by Fondecyt 1100936 (L.F.B.) and 3085021 (C.A). G.E.S. was supported by NIH Grants DK050594 and HL061974. I.R. is a Conicyt Fellow and received a "Beca de Apoyo a la Tesis Doctoral" from Conicyt. G.E.S. is supported by NIH Grant DK050594. The Centro de Estudios Científicos is funded by the Chilean Government through the Centers of Excellence Base Financing Program of Conicyt and Gobierno Regional de Los Ríos. We thank Karin Alegría for technical assistance, veterinary Dr. Viviana Bustos for assistance with NBCe1 KO animals, and Karen Everett for critical reading of this manuscript. 50859 was kindly provided by Juergen Puenter, Sanofi-Aventis, and human NBCe1A cDNA was kindly provided by Dr. Ashley Toye.

Correspondence should be addressed to L. Felipe Barros, Centro de Estudios Científicos, Casilla 1469, Valdivia, Chile. E-mail: fbarros@cecs.cl.

DOI:10.1523/JNEUROSCI.2310-11.2011

Copyright $\odot 2011$ the authors $\quad 0270-6474 / 11 / 3114264-08 \$ 15.00 / 0$ that may be involved (Dienel and Cruz, 2004; Bonvento et al., 2005; Pellerin et al., 2007; Magistretti, 2009; Barros and Deitmer, 2010; Jolivet et al., 2010). Using an optical method that measures the glycolytic rate with high spatiotemporal resolution (Bittner et al., 2010), we have observed that small increases in extracellular $\mathrm{K}^{+}$, such as measured in brain tissue during afferent stimulation, can exert a strong stimulatory effect on astrocytic glycolysis, a process that evolves within seconds and is quickly reversible after $\mathrm{K}^{+}$withdrawal (Bittner et al., 2011). $\mathrm{K}^{+}$-stimulated glycolysis was found to be sensitive to ouabain, suggesting a role for the canonical, negative feedback pathway that involves the $\mathrm{Na}^{+} / \mathrm{K}^{+}$ ATPase pump. However, glutamate, aspartate, and gramicidin, which increase intracellular $\mathrm{Na}^{+}$and effectively stimulate the sodium pump (Chatton et al., 2000; Porras et al., 2008), failed to activate glycolysis in the short term (Bittner et al., 2011), implying that $\mathrm{Na}^{+}$pump engagement is not sufficient for glycolytic stimulation and that a second signaling pathway may be involved.

\section{Materials and Methods}

Chemicals and tissue culture reagents were from Sigma. BCECF AM was obtained from Invitrogen. The construct coding for the sensor FLII ${ }^{12}$ Pglu600 $\mu \Delta 6$ (Takanaga et al., 2008) is available through www. addgene.org. Adenoviral vector Ad FLII ${ }^{12}$ Pglu $600 \mu \Delta 6$ was custom made by Vector Biolabs.

Animals, cell cultures, and tissue slices. Animals used were mixed F1 male mice $(\mathrm{C} 57 \mathrm{BL} / 6 \mathrm{~J} \times \mathrm{CBA} / \mathrm{J})$, kept in an animal room under SPF conditions at a room temperature of $20 \pm 2{ }^{\circ} \mathrm{C}$, in a $12 / 12 \mathrm{~h} \mathrm{light/dark}$ cycle with ad libitum access to food and water. NBCe1A null mice were mixed 129S6/SvEv and Black Swiss background, with wild-type age- 

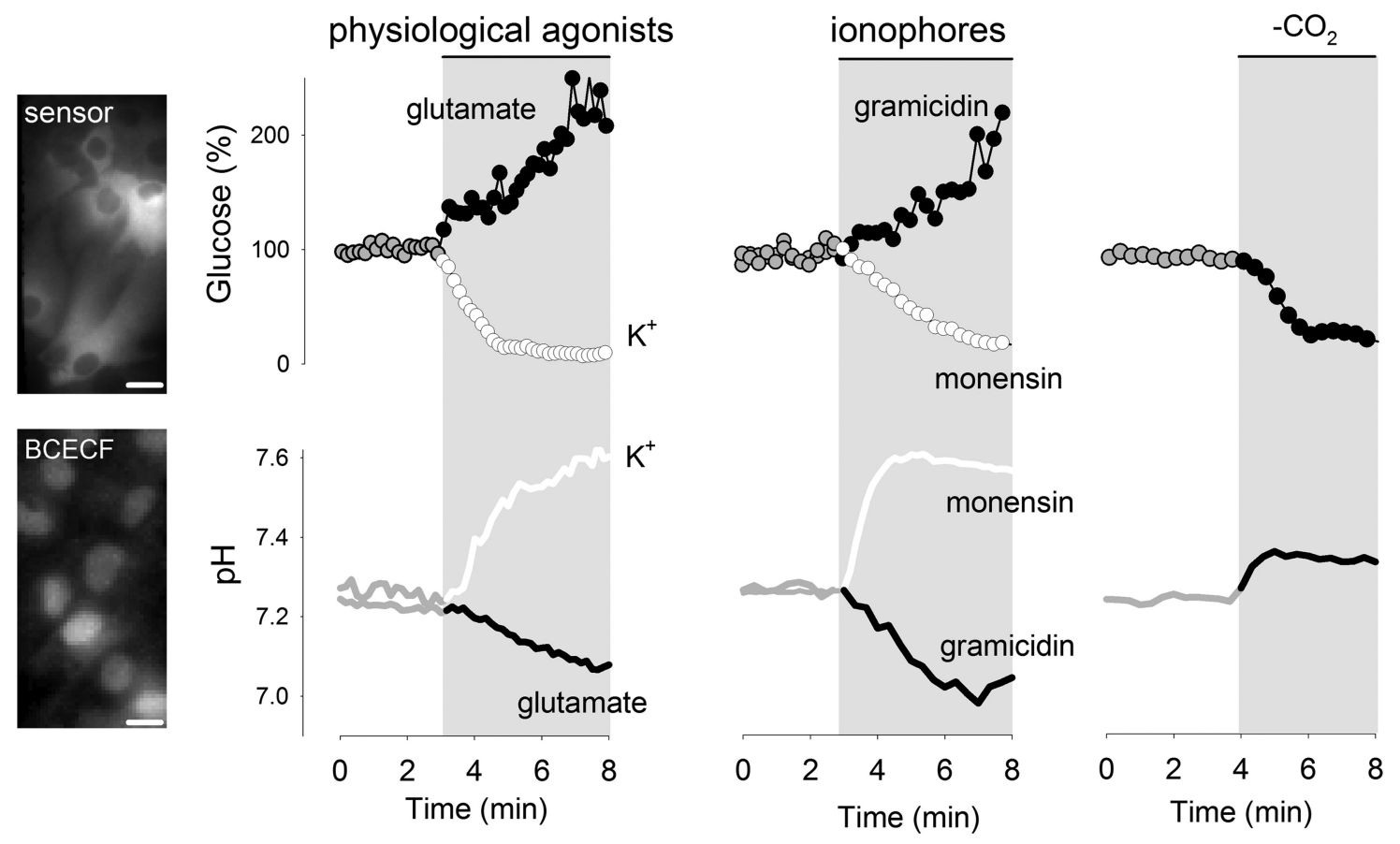

Figure 1. Acute modulation of astrocytic glycolysis by intracellular pH. Images on the left show astrocytes expressing the glucose sensor FLII ${ }^{12} \mathrm{Pglu} 600 \mu \Delta 6$ or loaded with BCECF, bars represent $10 \mu \mathrm{m}$. The effects of $\mathrm{K}^{+}(12 \mathrm{~mm})$, glutamate $(50 \mu \mathrm{M})$, monensin $(100 \mu \mathrm{M})$, and gramicidin $(20 \mu \mathrm{g} / \mathrm{ml})$ on intracellular glucose concentration and pH were measured as described in Materials and Methods. Intracellular glucose and pH were measured during transition between $\mathrm{HCO}_{3}^{-}$buffers of equal pH, with and without $5 \% \mathrm{CO}_{2}$. All traces correspond to representative plots of at least three independent experiments.

matched littermates serving as controls. Animals were genotyped by PCR analysis (Gawenis et al., 2007). Experiments were approved by the Centro de Estudios Científicos Animal Care and Use Committee. Mixed cortical cultures of neuronal and glial cells (1- to 3-d-old neonates), cultures of hippocampal neurons ( $17.5 \mathrm{~d}$ embryos), and organotypic hippocampal slices (30-60 d adults) were prepared as detailed previously (Bittner et al., 2010). The hyperpolarized cell line HEKT2 line was created by stable transfection of the background potassium channel TASK2 (Niemeyer et al., 2001) (Mus musculus TASK-2, GenBank accession No. AF319542) in HEK293 cells using geneticin $(900 \mu \mathrm{g} / \mathrm{ml})$ for selection purposes. Cultures were transfected at days 5-7 (cortical) or 3-4 (hippocampal) with 5 $\mu \mathrm{g}$ of plasmid DNA, FLII ${ }^{12}$ Pglu600 $\mu \Delta 6$, and/or NBCe1A (Toye et al., 2006), using Lipofectamine 2000 (Invitrogen) or, alternatively, exposed to $5 \times 10^{6} \mathrm{PFU}$ of FLII ${ }^{12} \mathrm{Pglu} 600 \mu \Delta 6$ (cortical cultures and slices). For NBCe1A transfection, hippocampal neurons were cultured in the absence of bicarbonate/CO $\mathrm{CO}_{2}$ (HEPES-DMEM, Sigma). Measurements were performed after $24 \mathrm{~h}$.

Protein extraction and immunoblot analysis. HEK cells transfected with NBCe1A and primary culture cells were scraped into cold PBS $(1 \times)$ followed by centrifugation at $5000 \mathrm{rpm}$ for $5 \mathrm{~min}$ at $4^{\circ} \mathrm{C}$. The cell pellet was then suspended in cold RIPA $1 \times$ (radioimmunoprecipitation assay) lysis buffer (50 mu Tris- $\mathrm{HCl}, \mathrm{pH}$ 7.4, $150 \mathrm{~mm} \mathrm{NaCl}, 0.1 \%$ SDS, $0.5 \%$ sodium deoxycholate, $1 \%$ Nonidet P40, $10 \mathrm{~mm} N$-ethylmaleimide, 0.1 mu phenylmethylsulfonyl fluoride, $1 \mu \mathrm{g} / \mathrm{ml}$ aprotinin, $1 \mu \mathrm{g} / \mathrm{ml}$ leupeptin, and $1 \mu \mathrm{g} / \mathrm{ml}$ pepstatin A). After $30 \mathrm{~min}$ on ice, unlysed cells and nuclei were pelleted at $12,000 \mathrm{rpm}$ for $15 \mathrm{~min}$ at $4^{\circ} \mathrm{C}$. The protein concentration of the supernatant was determined by Bio-Rad Dc Protein Assay using BSA standards. For immunoblotting, protein samples (50 $\mu \mathrm{g})$ were loaded onto $8 \%(\mathrm{w} / \mathrm{v})$ SDS-polyacrylamide gels and electrotransferred onto nitrocellulose membranes. Blots were probed with a 1:1000 dilution of rabbit polyclonal anti-NBCe1A antibody (antiSLC4A4 of Abcam) and visualized with a secondary antibody conjugated to peroxidase-labeled goat anti-rabbit antibody to a dilution of 1:25,000. The signal was revealed using a chemiluminescence kit (Thermo Scientific, Pierce) following the manufacturer's instructions.

Electrophysiological recordings. Mouse cortical astrocytes from confluent day 7-9 cultures were subcultured into $35 \mathrm{~mm}$ Petri dishes and su- perfused with a bathing solution containing (in $\mathrm{mm}$ ) $136 \mathrm{NaCl}, 3 \mathrm{KCl}$, $1.25 \mathrm{CaCl}_{2}, 1.25 \mathrm{MgCl}_{2}$, 2 glucose, $10 \mathrm{HEPES} /$ Tris, pH 7.4, $300 \mathrm{mOsm}$ (achieved by the addition of appropriate amounts of sucrose). The pipette solution contained (in $\mathrm{mM}$ ) $35 \mathrm{KCl}, 105 \mathrm{~K}$-gluconate, $2 \mathrm{MgCl}_{2}, 0.5$ $\mathrm{CaCl}_{2}, 5$ EGTA, $2 \mathrm{Na}_{3} \mathrm{ATP}$, and 10 HEPES, pH 7.3. HEK cells were seeded on $35 \mathrm{~mm}$ dishes and superfused with a bathing solution containing 110 mм NaCl, $5 \mathrm{~mm} \mathrm{KCl}, 1.25 \mathrm{~mm} \mathrm{CaCl}_{2}, 1.25 \mathrm{~mm} \mathrm{MgSO}_{4}, 24 \mathrm{~mm} \mathrm{NaHCO}_{3}$, and $10 \mathrm{~mm}$ HEPES/Tris, $\mathrm{pH}$ 7.4. Osmolarity was adjusted with sucrose to a final value of $324 \mathrm{mOsm}$. Pipette solution contained $132 \mathrm{~mm}$ K-gluconate, $8 \mathrm{~mm} \mathrm{KCl}, 1 \mathrm{~mm} \mathrm{MgCl}, 15 \mathrm{~mm} \mathrm{NaHCO}_{3}, 10$ mм EGTA, 1 mM Na $\mathrm{N}_{3} \mathrm{ATP}, 0.1 \mathrm{~mm}$ GTP, and $10 \mathrm{~mm}$ HEPES, pH 7.2, $314 \mathrm{mOsm}$. Extracellular solutions were equilibrated with $5 \% \mathrm{CO}_{2} / 95 \% \mathrm{O}_{2}$. Higher $\mathrm{K}^{+}$concentrations were obtained by equimolar replacement of $\mathrm{Na}^{+}$. Standard whole-cell patch-clamp recordings were performed using an EPC-7 (List Medical) amplifier. The bath was grounded via an agar bridge. Patch-clamp pipettes were made from thin borosilicate (hard) glass capillary tubing with an outside diameter of $1.5 \mathrm{~mm}$ (Harvard Apparatus) using a P-97 puller (Sutter Instruments). The pipettes had a resistance of 2.5-4 M $\Omega$. Voltage and current signals from the amplifier were digitized using a computer equipped with a Digidata 1322A or 1200 $\mathrm{AD} / \mathrm{DA}$ interface (Molecular Devices). The voltage pulse generator and analysis programs were from Molecular Devices. Corrections for changes in junction potential were made.

Glucose and $\mathrm{pH}$ imaging. Experiments were performed at room temperature $\left(22-25^{\circ} \mathrm{C}\right)$. The methodology to measure glucose and the glycolytic rate has been described in detail (Bittner et al., 2010). Previously, we showed that the acute modulation of astrocytic glycolysis by $\mathrm{K}^{+}$is also present at $36^{\circ} \mathrm{C}$ (Bittner et al., 2011). Cells were imaged in a $95 \%$ air $/ 5 \% \mathrm{CO}_{2}$-gassed solution of the following composition (in $\mathrm{mM}$ ): 112 $\mathrm{NaCl}, 1.25 \mathrm{CaCl}_{2}, 1.25 \mathrm{MgSO}_{4}, 1-2$ glucose, 1 sodium lactate, $10 \mathrm{HEPES}$, and $24 \mathrm{NaHCO}_{3}, \mathrm{pH} 7.4$, with $3 \mathrm{~mm} \mathrm{KCl}$ (astrocytes and neurons) or 5 $\mathrm{mm} \mathrm{KCl}(\mathrm{HEK})$. Brain slices were superfused with a $95 \% \mathrm{O}_{2} / 5 \% \mathrm{CO}_{2}$ gassed buffer containing the following (in $\mathrm{mm}$ ): $139.5 \mathrm{NaCl}, 3 \mathrm{KCl}, 1.25$ $\mathrm{NaH}_{2} \mathrm{PO}_{4}, 2 \mathrm{CaCl}_{2}, 1 \mathrm{MgCl}_{2}, 2$ glucose, 1 sodium lactate, and 26 $\mathrm{NaHCO}_{3}$, pH 7.4. For $\mathrm{Ba}^{2+}$ experiments, $\mathrm{MgSO}_{4}$ was replaced by $\mathrm{MgCl}_{2}$ to avoid precipitation. Experiments with gramicidin and monensin were in the following solution (in $\mathrm{mm}$ ): $136 \mathrm{NaCl}, 3 \mathrm{KCl}, 1.25 \mathrm{CaCl}_{2}, 1.25$ 
$\mathrm{MgCl}_{2}, 1-2$ glucose, 1 sodium lactate, and 10 HEPES, pH 7.4. When using higher $\mathrm{K}^{+}$concentrations, $\mathrm{NaCl}$ was adjusted to maintain isotonicity. Cultures were imaged with an Olympus IX70 or with an Olympus BX51 microscope respectively equipped with a $40 \times$ oilimmersion objective (NA 1.3) or with a $20 \times$ water-immersion objective (NA 0.95). The microscopes were equipped with Cairn monochromators and a Hamamatsu Orca camera controlled by Kinetics software or a Rollera camera controlled with Metafluor software. For nanosensor ratio measurements, cells were sequentially excited at 430 and $512 \mathrm{~nm}(0.2$ and $0.025 \mathrm{~s}$, respectively). Emissions were collected at $535 \pm 15 \mathrm{~nm}$. Citrine correction of $\mathrm{pH}$ effects were as detailed in the article describing the glycolytic rate method (Bittner et al., 2010). BCECF was ester loaded at $0.1 \mu \mathrm{M}$ for 3-4 min and the signal was calibrated by exposing the cultures to solutions of different $\mathrm{pH}$ after permeabilizing the cells with $10 \mu \mathrm{g} / \mathrm{ml}$ nigericin and $20 \mu \mathrm{g} / \mathrm{ml}$ gramicidin in an intracellular buffer (Castro et al., 2004). BCECF was sequentially excited at 440 and $490 \mathrm{~nm}(0.1$ and $0.05 \mathrm{~s}$ ) and imaged at $535 \pm 15 \mathrm{~nm}$.

Statistical analysis. All time courses shown represent single cells. Regression analyses were performed with the computer program SigmaPlot (Jandel). Data are presented as means \pm $\operatorname{SEM}(n=$ number of experiments, with a minimum of 6 cells per experiment). Differences in mean values of paired samples were evaluated with the Student's $t$ test. $p$ values $<0.05$ were considered significant and are indicated with an asterisk $\left(^{*}\right)$.

\section{Results}

Acute modulation of glycolysis by intracellular $\mathrm{pH}$

The short-term effects of glutamate and $\mathrm{K}^{+}$ on astrocytic glycolysis are opposite (Bittner et al., 2011), as are the effects of these molecules on intracellular $\mathrm{pH}$ (Fig. 1). This correlation, together with the notion that phosphofructokinase (PFK), the control point of glycolysis, is sensitive to $\mathrm{pH}$ (Trivedi and Danforth, 1966; Erecińska et al., 1995), suggested intracellular $\mathrm{pH}$ as a possible signal linking $\mathrm{K}^{+}$and astrocytic glycolysis. To test this possibility, we first used the ionophores gramicidin and monensin, which cause opposite effects on intracellular $\mathrm{pH}$; gramicidin transports protons into cells and acidifies, whereas monensin is a $\mathrm{Na}^{+} / \mathrm{H}^{+}$exchanger that induces alkalinization. As shown previously, the concentration of glucose increased in response to gramicidin due to glucose transporter stimulation without changes in the rate of glycolysis (Bittner et al., 2011). In contrast, monensin caused a decrease in intracellular glucose (Fig. 1), with a glycolytic rate stimulation of $352 \pm 151 \%$ $(n=3$ experiments, $p<0.05)$ measured using the cytochalasin $\mathrm{B}$ protocol (see Materials and Methods).

The contrasting glycolytic effects of gramicidin and monensin seem at odds with a major controlling role for the $\mathrm{Na}^{+}$pump, for both gramicidin and monensin augment intracellular $\mathrm{Na}^{+}$and stimulate the pump. Control experiments with SBFI-loaded cells showed that gramicidin was even more effective than monensin in

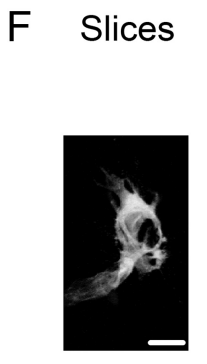

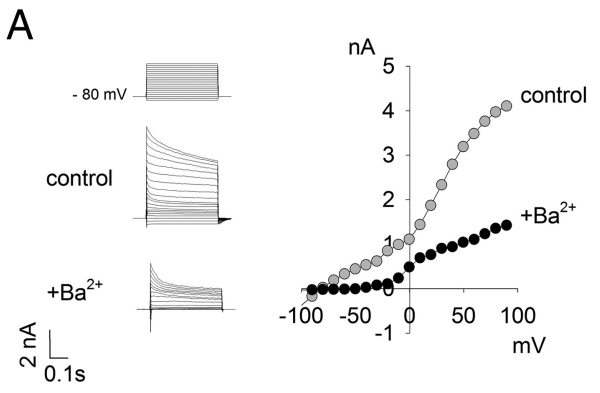
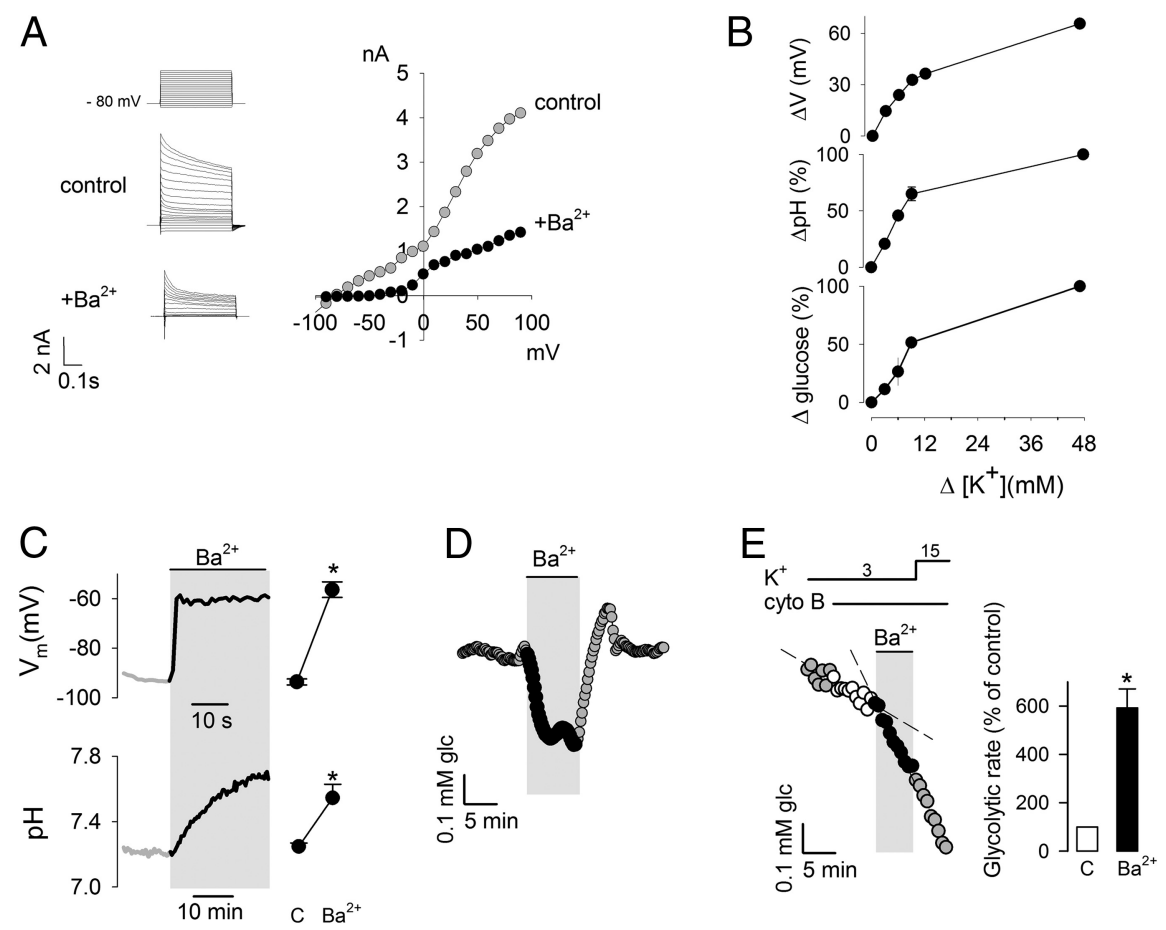

Figure 2. Acute modulation of astrocytic glycolysis by membrane depolarization. $\boldsymbol{A}$, The current/voltage relationship in cortical astrocytes was registered by patch clamping as described in Materials and Methods. Currents were recorded from a holding potential of $-80 \mathrm{mV}$ at variable $500 \mathrm{~ms}$ test pulses from -100 to $+100 \mathrm{mV}$, in the absence and presence of $3 \mathrm{~mm} \mathrm{Ba}^{2+} . \boldsymbol{B}$, Effect re representative of three independent experiments. Initial rates of $\mathrm{pH}$ increase and glucose decrease were estimated over $3 \mathrm{~min}$. C, Membrane potential and intracellular pH was measured before and after exposure to $3 \mathrm{~mm} \mathrm{Ba}^{2+}$. Bars summarize data from ments. $\boldsymbol{E}$, Sequential effects of $3 \mathrm{~mm} \mathrm{Ba}^{2+}$ and $15 \mathrm{~mm} \mathrm{~K}^{+}$on the glycolytic rate of a single astrocyte. Bars summarize data from the effects of $12 \mathrm{~mm} \mathrm{~K}^{+}$and $3 \mathrm{~mm} \mathrm{Ba}^{2+}$ on intracellular glucose in the presence and absence (HEPES) of $\mathrm{HCO}_{3}^{-}$. Data are representative of three separate experiments.

terms of the $\mathrm{Na}^{+}$overload (data not shown), implying that the inhibitory effect of an acid $\mathrm{pH}$ can override the stimulatory effect of adenine nucleotides, a conclusion that was also reached in a study of astrocytic ischemia (Swanson et al., 1997). In a separate strategy to manipulate intracellular $\mathrm{pH}, \mathrm{CO}_{2}$ was acutely withdrawn from the perfusate. This maneuver increased $\mathrm{pH}$ and decreased intracellular glucose concentration (Fig. 1), with a glycolytic rate stimulation of $150 \pm 45 \%(n=3$ experiments, $p<0.05)$. These results show that intracellular $\mathrm{pH}$ can modulate astrocytic glycolysis on its own and that the effect can be fast and may surpass that of the $\mathrm{Na}^{+}$/sodium pump pathway.

Acute stimulation of glycolysis by membrane depolarization The $\mathrm{pH}$ change induced in astrocytes by a rise in extracellular $\mathrm{K}^{+}$ is mediated by plasma membrane depolarization, a response present in vivo that has been termed depolarization-induced 


\section{A Genetic deletion}
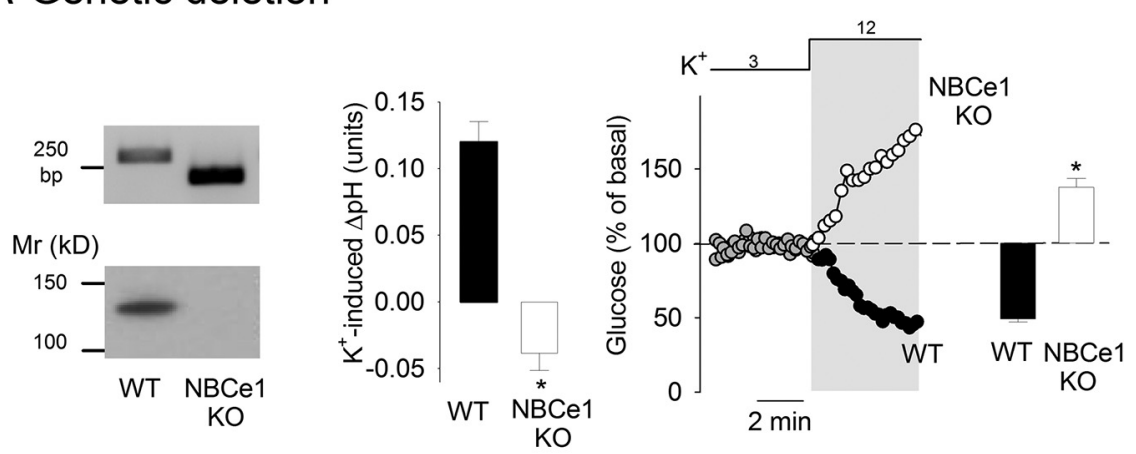

\section{B Functional inhibition}
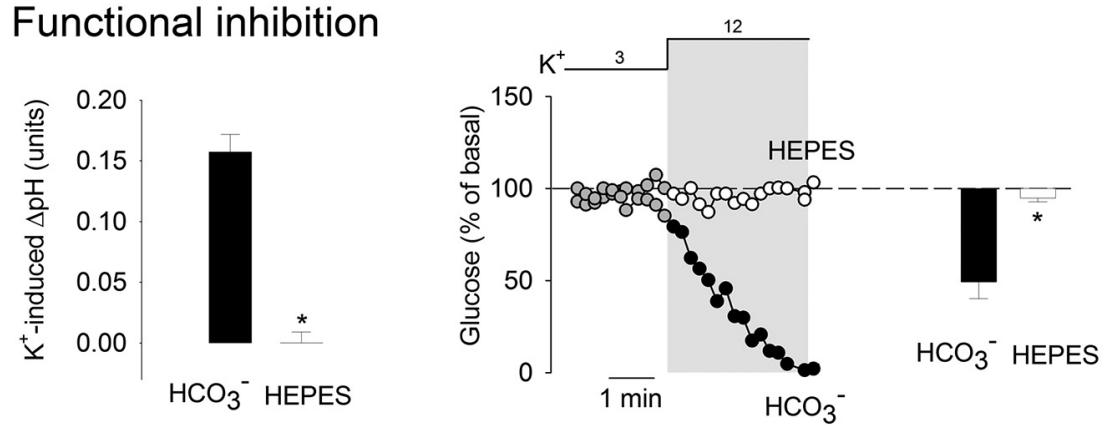

\section{Pharmacological inhibition}

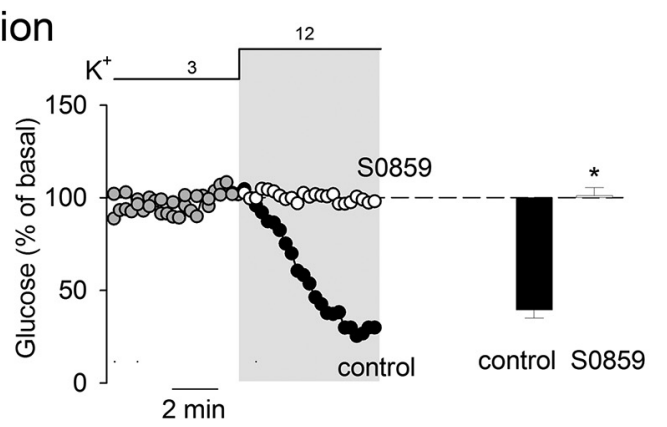

Figure 3. NBCe1 is necessary for $\mathrm{K}^{+}$-stimulated glycolysis in astrocytes. $\boldsymbol{A}$, Genetic deletion of NBC 1 . The left panel illustrates the results of PCR genotyping of tail biopsies and Western blotting analysis of cultured astrocytes from wild-type (WT) and NBCe1 knock-out mice (KO). Bars in the middle represent the changes in intracellular pH elicited by a 3 min exposure to $12 \mathrm{~mm} \mathrm{~K}^{+}$in WT $(n=3)$ and NBCe1 KO astrocytes $(n=7)$. The impact of a 3 min exposure to $12 \mathrm{~mm} \mathrm{~K}^{+}$on glucose concentration in WT and NBCe1 $\mathrm{KO}$ astrocytes is illustrated by the time course and bar graph on the right $(n=3-4)$. $\boldsymbol{B}$, Bicarbonate omission. Bars on the left illustrate $\mathrm{pH}$ changes elicited by a $3 \mathrm{~min}$ exposure to $12 \mathrm{mM} \mathrm{K}^{+}$in the presence and absence (HEPES) of bicarbonate $(n=4)$. Middle, The effect of $12 \mathrm{~mm} \mathrm{~K}^{+}$on glucose concentration was measured over time in the presence and absence (HEPES) of bicarbonate. Bars on the right show the change in intracellular glucose after $3 \mathrm{~min}(n=3)$. C, S0859. Bars on the left illustrate $\mathrm{pH}$ changes elicited by a $3 \mathrm{~min}$ exposure to $12 \mathrm{~mm} \mathrm{~K}^{+}$before and after a $4 \mathrm{~min}$ preincubation with $30 \mu \mathrm{m} \mathrm{S0859}(n=3)$. Middle, The effect of $12 \mathrm{~mm} \mathrm{~K}^{+}$on glucose concentration was measured before and after a 4 min preincubation with $30 \mu \mathrm{m} \mathrm{S0859}(n=3)$. Bars on the right show the change in intracellular glucose after $3 \min (n=3)$.

alkalinization and requires expression of the NBCe1, an electrogenic membrane transporter that carries one $\mathrm{Na}^{+}$and two $\mathrm{HCO}_{3}^{-}$molecules per catalytic cycle (Chesler and Kraig, 1987; Chesler and Kraig, 1989; Deitmer and Szatkowski, 1990; Pappas and Ransom, 1994). Because of their dominant potassium permeability, the membrane potential in astrocytes is optimally sensitive to extracellular $\mathrm{K}^{+}$(Fig. $2 A, B$ ). At rest, the membrane potential is close to the reversal potential of the NBCe1, and therefore, there is little or no $\mathrm{HCO}_{3}^{-}$flux. Synaptic activity increases extracellular $\mathrm{K}^{+}$, astrocytes depolarize, $\mathrm{HCO}_{3}^{-}$enters the cells through the $\mathrm{NBCe1}$, and intracellular $\mathrm{pH}$ goes up. In agreement with functional NBCe1 expression in our cultures, intracellular $\mathrm{pH}$ was sensitive to small rises in extracellular $\mathrm{K}^{+}$(Fig. 2 B). Consistent with a metabolic role for NBCe1-mediated $\mathrm{pH}$ changes, the sensitivity to $\mathrm{K}^{+}$of glucose usage was similar to that of membrane potential and $\mathrm{pH}$ (Fig. $2 B$ ). To depolarize the cells independently of $\mathrm{K}^{+}$, we applied $\mathrm{Ba}^{2+}$, which blocks $\mathrm{K}^{+}$ channels and is not an extracellular substrate for the $\mathrm{Na}^{+} / \mathrm{K}^{+}$ATPase (Gatto et al., 2007). Figure $2 C$ shows that $\mathrm{Ba}^{2+}$ exposure resulted in a membrane depolarization of $>35 \mathrm{mV}$, which led to intracellular alkalinization (Fig. 2D). The extents of both depolarization and alkalinization were similar to those achieved by $12 \mathrm{~mm} \mathrm{~K}^{+}$. Supporting a metabolic role for the $\mathrm{NBCe} 1, \mathrm{Ba}^{2+}$ caused a strong acute stimulation of astrocytic glycolysis in primary culture cells and in tissue slices (Fig. 2E,F).

\section{NBCel involvement in $\mathrm{K}^{+}$-stimulated glycolysis}

Three strategies were followed to study astrocytic glycolysis in the absence of NBCe1 activity. The NBCe1 is encoded by the Slc4a4 gene, for which a null mutant mouse is available (Gawenis et al., 2007). NBCe1 null mice die 2 weeks after birth due to a systemic acidosis of renal origin, but their brain tissue does not present gross morphological alterations as analyzed by light microscopy. Astrocytes cultured from neonatal NBCe1 null mice did not present detectable NBCe1 activity, measured as the rate of $\mathrm{pH}$ recovery after an acid load (data not shown). Figure $3 A$ shows that, in contrast to astrocytes from wild-type littermates, astrocytes from NBCe1 null mice responded to high extracellular $\mathrm{K}^{+}$with an increase in glucose concentration, consistent with an inhibition of glycolysis. In NBCe1 $\mathrm{KO}$ astrocytes, the alkalinization induced by $\mathrm{CO}_{2}$ withdrawal caused a decrease in glucose concentration similar to that observed in wild-type cells (data not shown), demonstrating that the glycolytic machinery was not directly compromised by NBCe1 deletion. Next, NBCe1 function was inhibited by replacing $\mathrm{HCO}_{3}^{-} / \mathrm{CO}_{2}$ with a HEPES buffer, in which bicarbonate levels, though not zero, are greatly reduced as is NBCe1 activity (Deitmer and Rose, 1996). In HEPES buffer, extracellular $\mathrm{K}^{+}$ failed to alkalinize the cells and also failed to activate glucose metabolism, both in culture and in slices (Figs. 2F, 3B). Finally, NBCe1 activity was blocked pharmacologically with S0859, an $\mathrm{N}$-cyanosulfonamide that reversibly abrogates NBCe1 activity in cardiomyocytes (Ch'en et al., 2008). In astrocytes, S0859 was found to be an effective NBCe1 blocker (data not shown). As shown in Figure 3C, S0859 inhibited the alkalinization induced by $\mathrm{K}^{+}$and prevented the effect of $\mathrm{K}^{+}$on glucose metabolism.

Reconstitution of $\mathrm{K}^{+}$-stimulated glycolysis in HEK293 cells Having demonstrated a necessary role for the NBCel in the glycolytic effect of $\mathrm{K}^{+}$, we investigated the possible presence of additional astrocyte-specific factors using HEK293 cells as a 
template. To make membrane potential sensitive to extracellular $\mathrm{K}^{+}$, a stable cell line HEKT2 was first generated that overexpresses the background potassium channel TASK2. These cells show outward currents at depolarized membrane potentials (Fig. 4A) and a shift in resting membrane potential from $-17 \pm 3 \mathrm{mV}(n=5)$ to $-61 \pm 3 \mathrm{mV}(n=6)$. An increase in extracellular $\mathrm{K}^{+}$from 5 to $30 \mathrm{~mm}$ depolarized HEKT 2 cells by $30 \pm 4 \mathrm{mV}(n=6)$, similar to the depolarization obtained in astrocytes while switching from 3 to 12 $\mathrm{mM} \mathrm{K}{ }^{+}$(Fig. 2B). HEKT2 cells lack NBCe1 protein expression and detectable NBCel activity (Fig. 4B). Transient expression of human NBCleA conferred HEKT2 with robust NBCe activity (Fig. $4 B)$. A rise in extracellular $\mathrm{K}^{+}$induced a small acidification in HEKT2 cells and a strong alkalinization in NBCe1Aexpressing HEKT2 cells (Fig. 4C). Thus, coexpression of a potassium channel and NBCe1A replicates the phenomenon of depolarization-induced alkalinization. Whereas a rise in extracellular $\mathrm{K}^{+}$did not affect glucose levels in HEKT2 cells, it did lead to strong glucose depletion in NBCe1A-expressing HEKT2 cells (Fig. $4 D)$. These results show that the phenomenon of $\mathrm{K}^{+}$-stimulated glycolysis does not require astrocytic-specific factors other than a predominant $\mathrm{K}^{+}$permeability and functional NBCe1.

\section{Effects of $\mathrm{K}^{+}$on neuronal glycolysis}

Neurons, being the actual source of elevated $\mathrm{K}^{+}$during activity, are also subject to the effects of $\mathrm{K}^{+}$. Figure $5 A$ shows that in response to a $\mathrm{K}^{+}$rise, cultured hippocampal neurons did not significantly modify their glucose concentration and acidified, reminiscent of the early effect of synaptic activity on neuronal $\mathrm{pH}$ (Chesler, 2003; Makani and Chesler, 2010; Svichar et al., 2011). $\mathrm{CO}_{2}$ removal resulted in acute glycolysis stimulation (Fig. $5 B$ ), consistent with previous long-term measurements of glycolysis with radioisotopes (Erecińska et al., 1995), so we tested whether the $\mathrm{NBCe} 1$ overexpression would endow them with $\mathrm{K}^{+}$-sensitive glycolysis as observed with HEK cells. Initially, NBCe1A expression was found to be toxic for neurons (as it was with wild-type HEK293 cells), perhaps due to unregulated influx of $\mathrm{Na}^{+}$and bicarbonate. Thus NBCe1A-transfected neurons had to be cultured in HEPES DMEM medium without added $\mathrm{CO}_{2}$. Figure $5 \mathrm{C}$ illustrates a prolonged experiment with NBCe1A-transfected neurons in which glucose was first measured using the FRET sensor and then cells were loaded with BCECF to corroborate functional NBCe1A expression. First, it was observed that a rise in extracellular $\mathrm{K}^{+}$caused a drop in glucose concentration that was $>10$ times faster in bicarbonate than in HEPES. Ensuing $\mathrm{pH}$ measurements in the same cells showed that $\mathrm{K}^{+}$elicited an alkalinization that was also $>10$ times faster in bicarbonate than in HEPES. The acidification during the switch from HEPES to $\mathrm{CO}_{2}$ /bicarbonate, which is due to fast $\mathrm{CO}_{2}$ diffusion into the cell, led to inhibition of glucose metabolism and higher intracellular glucose (Fig. 5C), an effect that had also been observed in astrocytes and HEK cells
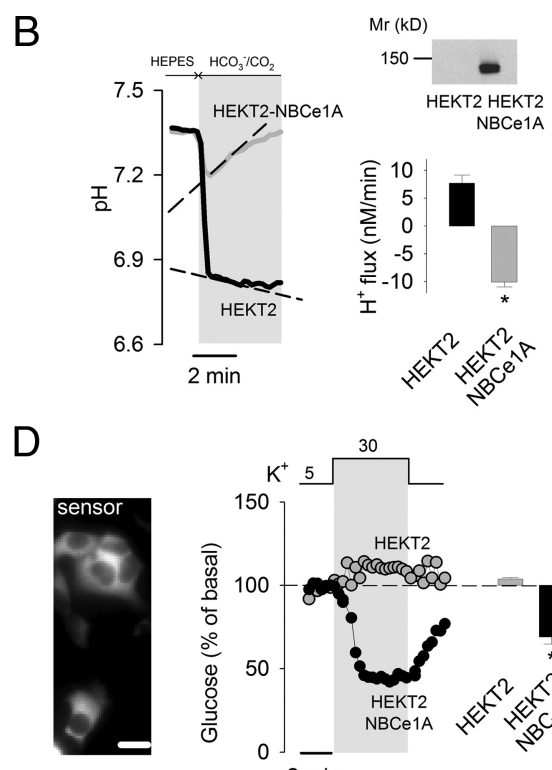

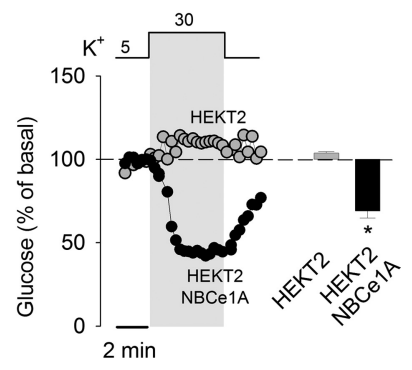

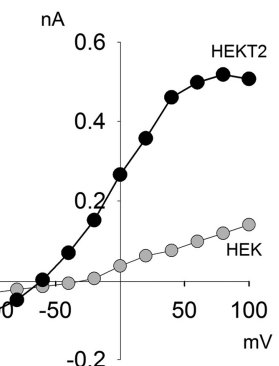

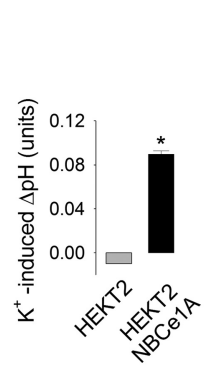

Figure 4. Assembly of ${ }^{+}{ }^{+}$-modulated glycolysis in HEK cells. $\boldsymbol{A}$, The steady-state current/voltage relationship in HEK and HEKT2 the change in glucose concentration after $3 \min (n=3)$.

(data not shown). These results show that neuronal glycolysis is acutely sensitive to changes in $\mathrm{pH}$ and that the $\mathrm{NBCe} 1$ is sufficient to endow neurons with $\mathrm{K}^{+}$-stimulated glycolysis. Mature hippocampal neurons in culture express functional NBCe1, which leads to a delayed intracellular alkalinization in response to high extracellular $\mathrm{K}^{+}$(Svichar et al., 2011). The lack of delayed $\mathrm{pH}$ rise in our cultures may be due to low or absent NBCe1 expression in younger neurons, and/or to dominant $\mathrm{Ca}^{2+}$-dependent acidification masking the NBCe1 response (Makani and Chesler, 2010).

\section{Discussion}

\section{NBCe1 participates in a feedforward pathway for} glycolysis regulation

In most mammalian cell types, glycolysis is regulated via the $\mathrm{Na}^{+} / \mathrm{K}^{+}$ATPase. This canonical mechanism is a negative feedback pathway, in which a $\mathrm{Na}^{+}$-stimulated pump decreases the $\mathrm{ATP} /(\mathrm{ADP}+\mathrm{AMP})$ ratio, leading to allosteric activation of glycolytic enzymes and compensatory ATP synthesis. In astrocytes, the canonical pathway can be activated by extracellular glutamate via the $\mathrm{Na}^{+}$/glutamate cotransporter (Pellerin et al., 2007). In a recent article, we have reported that extracellular $\mathrm{K}^{+}$, which is released by active neurons, behaves as a fast agonist of glycolysis in astrocytes and that the effect is sensitive to inhibition of the sodium pump (Bittner et al., 2011). However, we show here that the glycolytic response to $\mathrm{K}^{+}$is not mediated by the canonical pathway, which only plays a permissive role, but by an alternative cascade involving $\mathrm{K}^{+}$, membrane potential, the NBCe1, and intracellular $\mathrm{pH}$, the $\mathrm{KPNH}$ pathway. Unlike the conventional pathway, the KPNH pathway is not a negative feedback but rather a feedforward, whereby an astrocyte, prompted by active neurons, anticipates its own needs for fuel in the form of ATP and the 


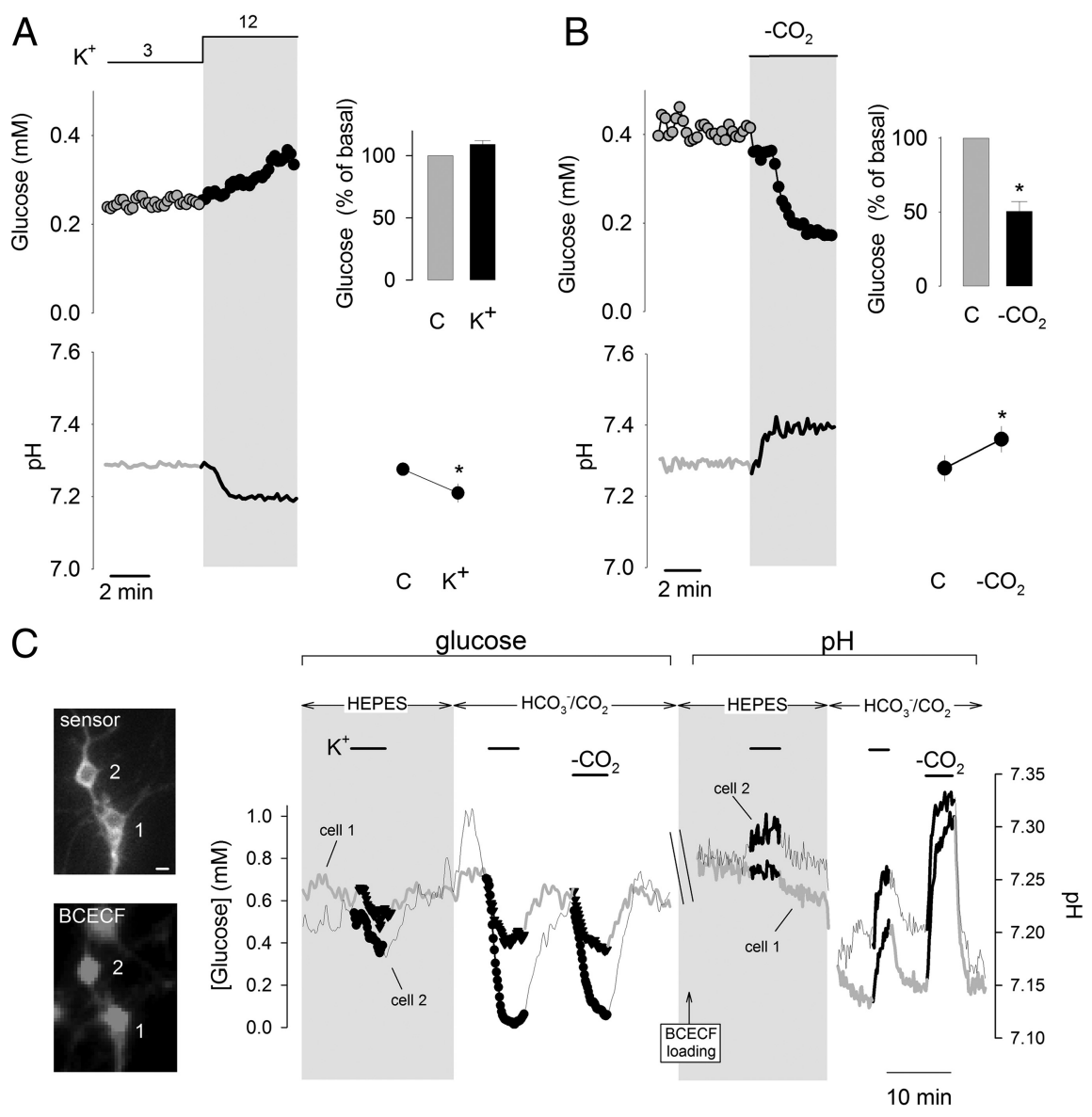

Figure 5. Lack of $\mathrm{K}^{+}$-stimulated glycolysis in hippocampal neurons is explained by absence of NBCe1. $\boldsymbol{A}$, Time course of the effects of $12 \mathrm{~mm} \mathrm{~K}^{+}$on neuronal glucose (top) and pH (bottom). Graphs on the right summarize the changes after $3 \mathrm{~min}$ of exposure ( $n=3$ or 4). $\boldsymbol{B}$, Time course of the effect of $\mathrm{CO}_{2}$ removal on neuronal glucose (top) and pH (bottom). Changes after 3 min are summarized on the right $(n=3)$. $C$, Neurons were cotransfected with CDNAs coding for the FRET glucose sensor and NBCe1A, bars represent $10 \mu \mathrm{m}$. After monitoring glucose concentration, cells were AM loaded with BCECF, allowing for a series of pH measurements. The graph presents the effect of $12 \mathrm{~mm} \mathrm{~K}^{+}$on glucose and pH in the presence and absence of $\mathrm{HCO}_{3}^{-} / \mathrm{CO}_{2}$ in two neurons of different morphology. The acute alkalinization observed in response to high $\mathrm{K}^{+}$demonstrates functional NBCe in these two neurons. Similar results were obtained in six independent experiments.

needs of neurons in the form of lactate. Considering the role proposed for lactate in neurovascular coupling (Gordon et al., 2008), the KPNH pathway may also help to anticipate the local need for oxygen. Astrocytes can also be depolarized by other mechanisms, for example, engagement of ionotropic glutamate receptors and $\alpha-1$ adrenergic receptors (Bowman and Kimelberg, 1984; Kettenmann and Schachner, 1985; Bowman and Kimelberg, 1987), which may also result in glycolytic stimulation.

In support of a role for the KPNH pathway in the regulation of astrocyte glycolysis, the following experimental evidence was collected: (1) a close correlation between the effects of $\mathrm{K}^{+}$on membrane potential, intracellular $\mathrm{pH}$, and glycolysis; (2) the rise in $\mathrm{pH}$ and concurrent glycolytic activation induced by $\mathrm{K}^{+}$-independent membrane depolarization; (3) the abrogation of the metabolic effect of $\mathrm{K}^{+}$by genetic, functional, and pharmacological inhibition of the NBCe1; and (4) the endowment of neurons and HEK cells with $\mathrm{K}^{+}$-dependent alkalinization and glycolysis stimulation by functional expression of the NBCe1. In favor of a physiological role for the KPNH pathway is the robustness of the $\mathrm{K}^{+}$response, which is independent of resting metabolic rate, temperature $\left(22-36^{\circ} \mathrm{C}\right)$, days in culture, and confluence. The phenomenon is also resistant to subculturing, independent of the presence of neurons and present in tissue slices (Bittner et al.,
2011). Another argument is that all individual components of the cascade are in place in vivo, including $\mathrm{K}^{+}$-sensitive membrane potential, NBCe1 expression, and activity-dependent astrocytic alkalinization (Chesler and Kraig, 1987, 1989; Deitmer and Rose, 1996; Schmitt et al., 2000; Chesler, 2003). The observation that cortical activity in vivo results in astrocytic alkalinization shows that the effect of $\mathrm{K}^{+}$surpasses that of acidifying factors such as glutamate and lactate. Judging from similar effects of $\mathrm{pH}$ on glycolysis in various contexts: astrocytes, HEK cells, neurons, synaptosomes, C6 glioma cells, muscle cells, and purified phosphofructokinase (Trivedi and Danforth, 1966; Fidelman et al., 1982; Erecińska et al., 1995; Swanson et al., 1997), the pH modulation of glycolysis appears to be a conserved microscopic property that is not likely to differ in vivo.

In addition, we observed that glycolysis in young neuronal cultures is insensitive to rises in extracellular $\mathrm{K}^{+}$and that their lack of NBCe is accountable for the deficit. However, an elegant study reported recently that mature hippocampal neuron do express NBCe and respond to high extracellular $\mathrm{K}^{+}$with a biphasic $\mathrm{pH}$ response: an early acidification, followed minutes later by a rebound alkalinization (Svichar et al., 2011). The biphasic response was dissected as the net result of two simultaneous and independent mechanisms: transient acid influx mediated by the PMCA (Makani and Chesler, 2010) and sustained but weaker acid extrusion mediated by the NBCe. The NBCe is expressed in some neuronal subpopulations in vivo (Majumdar and Bevensee, 2010). It remains to be established whether the biphasic $\mathrm{pH}$ response in mature neurons is accompanied by corresponding changes in glycolytic rate.

\section{Interstitial $\mathrm{K}^{+}$concentration}

A relative unknown is the concentration of $\mathrm{K}^{+}$reached in brain interstitium during activity. Although a maximum "ceiling" $\mathrm{K}^{+}$ concentration of $12 \mathrm{~mm}$ has been measured with microelectrodes in the brain interstice during electrical afferent stimulation (Kofuji and Newman, 2004), direct extrapolation to physiological conditions is not possible, for exogenous stimulation recruits many more fibers than the intrinsic activity, resulting in supraphysiological $\mathrm{K}^{+}$release. An example of the levels reached by physiological $\mathrm{K}^{+}$release is the $4.7 \mathrm{~mm}$ measured in the spinal cord (Heinemann et al., 1990), but this value is regarded as an underestimate because it was also measured with microelectrodes, whose tips are much larger than the interstice $(100 \mu \mathrm{m}$ vs $20 \mathrm{~nm}$ ) and create a dead space that muffles the $\mathrm{K}^{+}$rise (Fröhlich et al., 2008). The actual concentration of $\mathrm{K}^{+}$at the synaptic cleft remains to be determined, but the fact that significant glycolytic effects were detected with a $\mathrm{K}^{+}$rise of just $1 \mathrm{~mm}$ and a $3 \mathrm{~mm}$ rise achieved stimulations of 200-300\% (Bittner et al., 2011) suggests that the phenomenon is of physiological relevance. Much higher 
extracellular $\mathrm{K}^{+}$concentrations do occur in traumatic injury, ischemia, seizures, and spreading depression (Kofuji and Newman, 2004), conditions that are accompanied by high rates of glucose consumption and lactate production and in which the KPNH pathway is likely to play pathogenic roles. Interestingly, energy-deficient neurological conditions like stroke and hypoxia induce changes in NBCel expression levels (Majumdar and Bevensee, 2010). Arguably, $\mathrm{K}^{+}$-stimulated astrocytes may outcompete neighboring neurons for glucose, with ensuing oxidative stress and neuronal apoptosis (Bolaños et al., 2010). $\mathrm{K}^{+}$may behave as a more general signal for fast neurometabolic coupling. Bergmann glial cells are rich in NBCe1, are highly permeable to $\mathrm{K}^{+}$, and are exposed to $\mathrm{K}^{+}$released from glutamatergic synapses at Purkinje cell dendrites. Other regions of possible relevance are the neuromuscular junction, the Ranvier node, and the serotoninergic synapse, where neuronal $\mathrm{K}^{+}$is released in the vicinity of glial cells. Astrocytes are heterogeneous in terms of $\mathrm{K}^{+}$channel expression and resting membrane potential (McKhann et al., 1997), which may determine different basal NBCe1 activity, different $\mathrm{pH}$ responses to extracellular $\mathrm{K}^{+}$, and therefore different metabolic responses.

\section{$\mathrm{pH}$ as a second messenger for glycolysis modulation}

By linking extracellular $\mathrm{K}^{+}$to glycolysis, $\mathrm{H}^{+}$behaves as a second messenger, though an unusual one that keeps its target under tonic inhibition. Other than the glucose transporter, flux control of glucose utilization is shared among three enzymes: hexokinase, PFK, and pyruvate kinase, and large increases in flux such as observed in response to $\mathrm{K}^{+}$must involve the three of them. Phosphofructokinase is sensitive to $\mathrm{pH}$ both in vitro and in cells, with steep $\mathrm{H}^{+}$concentration dependence (Trivedi and Danforth, 1966; Erecińska et al., 1995). Hexokinase may be recruited by the decrease in the concentration of its allosteric inhibitor, glucose6-phosphate, depleted as a result of PFK stimulation. Pyruvate kinase is activated allosterically by its substrate phosphoenolpyruvate and by fructose-1,6-bisphosphate, both of which are expected to rise after PFK activation. Thus it seems feasible that the KPNH pathway converges onto a single direct target, PFK. An analogous, albeit slower, regulation of glycolysis by intracellular $\mathrm{pH}$ has been reported in skeletal muscle, where the stimulation of the $\mathrm{Na}^{+} / \mathrm{H}^{+}$exchanger by insulin increases intracellular $\mathrm{pH}$, decreases glucose-6-phosphate levels (i.e. PFK stimulation), and activates glycolysis over a period of minutes (Fidelman et al., 1982). A commanding role for $\mathrm{pH}$ over astrocytic glycolysis may help to understand energy coupling during inhibitory neurotransmission. For instance, compared with glutamatergic activity, GABAergic activity is energetically inexpensive (Attwell and Laughlin, 2001). But as for glutamate, GABA is taken up by astrocytes via a $\mathrm{Na}^{+}$-coupled transporter, and it is not obvious how GABA uptake could avoid activating the astrocytic sodium pump and thus stimulating glycolysis (Chatton et al., 2003). One important difference between GABAergic transmission and glutamatergic transmission is that the former does not release $\mathrm{K}^{+}$. Moreover, astrocytes possess $\mathrm{HCO}_{3}^{-}$-permeable $\mathrm{GABA}_{\mathrm{A}}$ receptors, which when open release $\mathrm{HCO}_{3}^{-}$and acidify the cells (Kaila et al., 1991), which, as observed for glutamate, aspartate, and gramicidin, may counteract the stimulatory effect of $\mathrm{Na}^{+}$. This putative $\mathrm{GABA}_{\mathrm{A}}$-dependent glycolytic inhibition may perhaps match the inhibition of oxidative phosphorylation that follows intracellular acidification in astrocytes (Azarias et al., 2011). Excitatory and inhibitory neurotransmission crosstalk by opposite modulation of neuronal membrane potential; for the purposes of glycolysis modulation, excitatory and inhibitory neu- rotransmission may perhaps crosstalk by opposite modulation of astrocytic $\mathrm{pH}$.

\section{References}

Attwell D, Laughlin SB (2001) An energy budget for signaling in the grey matter of the brain. J Cereb Blood Flow Metab 21:1133-1145.

Azarias G, Perreten H, Lengacher S, Poburko D, Demaurex N, Magistretti PJ, Chatton JY (2011) Glutamate transport decreases mitochondrial pH and modulates oxidative metabolism in astrocytes. J Neurosci 31:35503559.

Barros LF, Deitmer JW (2010) Glucose and lactate supply to the synapse. Brain Res Rev 63:149-159.

Bittner CX, Loaiza A, Ruminot I, Larenas V, Sotelo-Hitschfeld T, Gutiérrez R, Córdova A, Valdebenito R, Frommer WB, Barros LF (2010) High resolution measurement of the glycolytic rate. Front Neuroenergetics 2:26.

Bittner CX, Valdebenito R, Ruminot I, Loaiza A, Larenas V, Sotelo-Hitschfeld T, Moldenhauer H, San Martín A, Gutiérrez R, Zambrano M, Barros LF (2011) Fast and reversible stimulation of astrocytic glycolysis by $\mathrm{K}^{+}$and a delayed and persistent effect of glutamate. J Neurosci 31:4709-4713.

Bolaños JP, Almeida A, Moncada S (2010) Glycolysis: a bioenergetic or a survival pathway? Trends Biochem Sci 35:145-149.

Bonvento G, Herard AS, Voutsinos-Porche B (2005) The astrocyte-neuron lactate shuttle: a debated but still valuable hypothesis for brain imaging. J Cereb Blood Flow Metab 25:1394-1399.

Bowman CL, Kimelberg HK (1984) Excitatory amino acids directly depolarize rat brain astrocytes in primary culture. Nature 311:656-659.

Bowman CL, Kimelberg HK (1987) Pharmacological properties of the norepinephrine-induced depolarization of astrocytes in primary culture: evidence for the involvement of an alpha 1-adrenergic receptor. Brain Res 423:403-407.

Caesar K, Hashemi P, Douhou A, Bonvento G, Boutelle MG, Walls AB, Lauritzen $M$ (2008) Glutamate receptor-dependent increments in lactate, glucose and oxygen metabolism evoked in rat cerebellum in vivo. J Physiol 586:1337-1349.

Castro J, Bittner CX, Humeres A, Montecinos VP, Vera JC, Barros LF (2004) A cytosolic source of calcium unveiled by hydrogen peroxide with relevance for epithelial cell death. Cell Death Differ 11:468-478.

Chatton JY, Marquet P, Magistretti PJ (2000) A quantitative analysis of L-glutamate-regulated $\mathrm{Na}+$ dynamics in mouse cortical astrocytes: implications for cellular bioenergetics. Eur J Neurosci 12:3843-3853.

Chatton JY, Pellerin L, Magistretti PJ (2003) GABA uptake into astrocytes is not associated with significant metabolic cost: implications for brain imaging of inhibitory transmission. Proc Natl Acad Sci USA 100:12456-12461.

Ch'en FF, Villafuerte FC, Swietach P, Cobden PM, Vaughan-Jones RD (2008) S0859, an N-cyanosulphonamide inhibitor of sodium-bicarbonate cotransport in the heart. Br J Pharmacol 153:972-982.

Chesler M (2003) Regulation and modulation of $\mathrm{pH}$ in the brain. Physiol Rev 83:1183-1221.

Chesler M, Kraig RP (1987) Intracellular pH of astrocytes increases rapidly with cortical stimulation. Am J Physiol 253:R666-R670.

Chesler M, Kraig RP (1989) Intracellular pH transients of mammalian astrocytes. J Neurosci 9:2011-2019.

Deitmer JW, Rose CR (1996) pH regulation and proton signalling by glial cells. Prog Neurobiol 48:73-103.

Deitmer JW, Szatkowski M (1990) Membrane potential dependence of intracellular $\mathrm{pH}$ regulation by identified glial cells in the leech central nervous system. J Physiol 421:617-631.

Dienel GA, Cruz NF (2004) Nutrition during brain activation: does cell-tocell lactate shuttling contribute significantly to sweet and sour food for thought? Neurochem Int 45:321-351.

Erecińska M, Deas J, Silver IA (1995) The effect of $\mathrm{pH}$ on glycolysis and phosphofructokinase activity in cultured cells and synaptosomes. J Neurochem 65:2765-2772.

Fidelman ML, Seeholzer SH, Walsh KB, Moore RD (1982) Intracellular pH mediates action of insulin on glycolysis in frog skeletal muscle. Am J Physiol 242:C87-C93.

Fox PT, Raichle ME, Mintun MA, Dence C (1988) Nonoxidative glucose consumption during focal physiologic neural activity. Science 241:462464.

Fröhlich F, Bazhenov M, Iragui-Madoz V, Sejnowski TJ (2008) Potassium 
dynamics in the epileptic cortex: new insights on an old topic. Neuroscientist 14:422-433.

Gatto C, Arnett KL, Milanick MA (2007) Divalent cation interactions with $\mathrm{Na}, \mathrm{K}-\mathrm{ATPase}$ cytoplasmic cation sites: implications for the paranitrophenyl phosphatase reaction mechanism. J Membr Biol 216:49-59.

Gawenis LR, Bradford EM, Prasad V, Lorenz JN, Simpson JE, Clarke LL, Woo AL, Grisham C, Sanford LP, Doetschman T, Miller ML, Shull GE (2007) Colonic anion secretory defects and metabolic acidosis in mice lacking the NBC1 Na+/. J Biol Chem 282:9042-9052.

Gordon GR, Choi HB, Rungta RL, Ellis-Davies GC, MacVicar BA (2008) Brain metabolism dictates the polarity of astrocyte control over arterioles. Nature 456:745-749.

Heinemann U, Schaible HG, Schmidt RF (1990) Changes in extracellular potassium concentration in cat spinal cord in response to innocuous and noxious stimulation of legs with healthy and inflamed knee joints. Exp Brain Res 79:283-292.

Hu Y, Wilson GS (1997a) A temporary local energy pool coupled to neuronal activity: fluctuations of extracellular lactate levels in rat brain monitored with rapid-response enzyme-based sensor. J Neurochem 69:1484-1490.

Hu Y, Wilson GS (1997b) Rapid changes in local extracellular rat brain glucose observed with an in vivo glucose sensor. J Neurochem 68:17451752.

Jolivet R, Allaman I, Pellerin L, Magistretti PJ, Weber B (2010) Comment on recent modeling studies of astrocyte-neuron metabolic interactions. J Cereb Blood Flow Metab 30:1982-1986.

Kaila K, Panula P, Karhunen T, Heinonen E (1991) Fall in intracellular pH mediated by GABAA receptors in cultured rat astrocytes. Neurosci Lett 126:9-12.

Kettenmann H, Schachner M (1985) Pharmacological properties of gamma-aminobutyric acid-, glutamate-, and aspartate-induced depolarizations in cultured astrocytes. J Neurosci 5:3295-3301.

Kofuji P, Newman EA (2004) Potassium buffering in the central nervous system. Neuroscience 129:1045-1056.

Lam TK, Gutierrez-Juarez R, Pocai A, Rossetti L (2005) Regulation of blood glucose by hypothalamic pyruvate metabolism. Science 309:943-947.

Magistretti PJ (2009) Role of glutamate in neuron-glia metabolic coupling. Am J Clin Nutr 90:875S-880S.

Majumdar D, Bevensee MO (2010) Na-coupled bicarbonate transporters of the solute carrier 4 family in the nervous system: function, localization, and relevance to neurologic function. Neuroscience 171:951-972.

Makani S, Chesler M (2010) Rapid rise of extracellular pH evoked by neural activity is generated by the plasma membrane calcium ATPase. J Neurophysiol 103:667-676.

McKhann GM 2nd, D’Ambrosio R, Janigro D (1997) Heterogeneity of astrocyte resting membrane potentials and intercellular coupling revealed by whole-cell and gramicidin-perforated patch recordings from cultured neocortical and hippocampal slice astrocytes. J Neurosci 17:6850-6863.

Niemeyer MI, Cid LP, Barros LF, Sepúlveda FV (2001) Modulation of the two-pore domain acid-sensitive $\mathrm{K}+$ channel TASK-2 (KCNK5) by changes in cell volume. J Biol Chem 276:43166-43174.

Pappas CA, Ransom BR (1994) Depolarization-induced alkalinization (DIA) in rat hippocampal astrocytes. J Neurophysiol 72:2816-2826.

Pellerin L, Magistretti PJ (1994) Glutamate uptake into astrocytes stimulates aerobic glycolysis: a mechanism coupling neuronal activity to glucose utilization. Proc Natl Acad Sci U S A 91:10625-10629.

Pellerin L, Bouzier-Sore AK, Aubert A, Serres S, Merle M, Costalat R, Magistretti PJ (2007) Activity-dependent regulation of energy metabolism by astrocytes: an update. Glia 55:1251-1262.

Porras OH, Ruminot I, Loaiza A, Barros LF (2008) $\mathrm{Na}(+)-\mathrm{Ca}(2+)$ cosignaling in the stimulation of the glucose transporter GLUT1 in cultured astrocytes. Glia 56:59-68.

Prichard J, Rothman D, Novotny E, Petroff O, Kuwabara T, Avison M, Howseman A, Hanstock C, Shulman R (1991) Lactate rise detected by $1 \mathrm{H}$ NMR in human visual cortex during physiologic stimulation. Proc Natl Acad Sci U S A 88:5829-5831.

Rinholm JE, Hamilton NB, Kessaris N, Richardson WD, Bergersen LH, Attwell D (2011) Regulation of oligodendrocyte development and myelination by glucose and lactate. J Neurosci 31:538-548.

Schmitt BM, Berger UV, Douglas RM, Bevensee MO, Hediger MA, Haddad GG, Boron WF (2000) $\mathrm{Na} / \mathrm{HCO}_{3}$ cotransporters in rat brain: expression in glia, neurons, and choroid plexus. J Neurosci 20:6839-6848.

Shimizu H, Watanabe E, Hiyama TY, Nagakura A, Fujikawa A, Okado H, Yanagawa Y, Obata K, Noda M (2007) Glial Nax channels control lactate signaling to neurons for brain $[\mathrm{Na}+]$ sensing. Neuron 54:59-72.

Silver IA, Erecińska M (1994) Extracellular glucose concentration in mammalian brain: continuous monitoring of changes during increased neuronal activity and upon limitation in oxygen supply in normo-, hypo-, and hyperglycemic animals. J Neurosci 14:5068-5076.

Suzuki A, Stern SA, Bozdagi O, Huntley GW, Walker RH, Magistretti PJ, Alberini CM (2011) Astrocyte-neuron lactate transport is required for long-term memory formation. Cell 144:810-823.

Svichar N, Esquenazi S, Chen HY, Chesler M (2011) Preemptive regulation of intracellular $\mathrm{pH}$ in hippocampal neurons by a dual mechanism of depolarization-induced alkalinization. J Neurosci 31:6997-7004.

Swanson RA, Farrell K, Stein BA (1997) Astrocyte energetics, function, and death under conditions of incomplete ischemia: a mechanism of glial death in the penumbra. Glia 21:142-153.

Takanaga H, Chaudhuri B, Frommer WB (2008) GLUT1 and GLUT9 as major contributors to glucose influx in HepG2 cells identified by a high sensitivity intramolecular FRET glucose sensor. Biochim Biophys Acta 1778:1091-1099.

Toye AM, Parker MD, Daly CM, Lu J, Virkki LV, Pelletier MF, Boron WF (2006) The human NBCe1-A mutant R881C, associated with proximal renal tubular acidosis, retains function but is mistargeted in polarized renal epithelia. Am J Physiol Cell Physiol 291:C788-C801.

Trivedi B, Danforth WH (1966) Effect of $\mathrm{pH}$ on the kinetics of frog muscle phosphofructokinase. J Biol Chem 241:4110-4112. 